\title{
Association Between Cemented vs Cementless Hemiarthroplasty and Short-Term Change of In-Hospital Mortality in Elderly Patients with Femoral Neck Fracture: A Propensity-Score Matching Analysis in a Multicenter Database
}

\author{
Takahisa Ogawa' \\ Toshitaka Yoshii \\ Atsushi Okawa' \\ Kiyohide Fushimi ${ }^{2}$ \\ Tetsuya Jinno (1D) ${ }^{1,3}$ \\ 'Department of Orthopaedic and Spine \\ Surgery, Tokyo Medical and Dental \\ University Graduate School of Medicine, \\ Tokyo, Japan; ${ }^{2}$ Department of Health \\ Policy and Informatics, Tokyo Medical and \\ Dental University Graduate School of \\ Medicine, Tokyo, Japan; ${ }^{3}$ Department of \\ Orthopaedic Surgery, Dokkyo Medical \\ University, Saitama Medical Center, \\ Saitama, Japan
}

Correspondence: Tetsuya Jinno Department of Orthopaedic Surgery, Dokkyo Medical University, Saitama Medical Center, 2-I-50 Minami-Koshigaya, Koshigaya, Saitama, 343-8555, Japan

Tel +8I-48-965- I I I I

Email jinnot@dokkyomed.ac.jp

Takahisa Ogawa

Department of Orthopaedic and Spine Surgery, Tokyo Medical and Dental

University Graduate School of

Medicine, I-5-45 Yushima, Bunkyo-ku,

Tokyo, II3-85 I9, Japan

Tel +8I-3-38|3-6III

Email takahisa.o@gmail.com
Objective: Cemented hemiarthroplasty is recommended for the vulnerable hip fracture population because of beneficial long-term outcomes. However, the association between cemented hemiarthroplasty and short-term mortality is controversial. To increase a preparedness of potential complication after cemented hemiarthroplasty, we aimed to evaluate the trajectory of the effect of cemented hemiarthroplasty on short-term in-hospital outcomes.

Methods: We investigated in-hospital mortality and complications between cemented hemiarthroplasty and cementless hemiarthroplasty using a nationwide multicenter database from 2010 to 2016 with a propensity-score matching analysis. We analyzed in-hospital mortality from 1 to 14 days after surgery. We also investigated in-hospital complications that may associate with mortality.

Results: After matching of 31,322 cases, we found no significant difference in 30-day inhospital mortality between the cemented and cementless hemiarthroplasty groups (hazard ratio, HR [95\% confidence interval, CI], 1.2 [0.89-1.6], p = 0.23). However, the 1- to 10-day postoperative mortality rates were significantly higher in the cemented group and the association becomes weaker as the postoperative period increased (day 1; HR [95\% CI]: 3.5 [1.6-7.68]; day 10; HR [95\% CI]: 1.59 [1.07-2.37]). The incidence of stroke and intensive care unit (ICU) admission was also significantly higher in the cemented group.

Conclusion: Cemented hemiarthroplasty was not significantly associated with an increase in overall in-hospital mortality but was significantly associated with short-term mortality from 1-day to 10-day after surgery. The incidence of stroke and ICU admission was also significantly higher in the cemented group. Surgeons should pay more attention to the risk of mortality and stroke in patients undergoing cemented hemiarthroplasty, especially in the early days of hospitalization.

Keywords: national database, complication, geriatric fracture, stroke, intensive care unit admission, ICU admission

\section{Introduction}

Hip fracture accounts for one fourth of all fractures in the elderly population, in which osteoporosis is a common health condition. ${ }^{1}$ Across the world, the aging population is expected to increase the incidence of hip fractures four times by $2050 .^{2}$ Most patients 
undergo surgical treatment especially for displaced femoral neck fracture because the risk of osteonecrosis or nonunion is high owing to the scarce blood supply around the femoral neck. $^{3}$

A recent study revealed that cemented hip hemiarthroplasty is more protective from implant-related complications, such as periprosthetic fracture or aseptic loosening than cementless hip hemiarthroplasty and also results in favorable long-term survival. ${ }^{4,5}$ On the other hand, several studies have reported adverse events when using cemented hemiarthroplasty, especially during surgery. One of the critical complications of cemented implantation is bone cement implantation syndrome (BCIS), which causes hypoxia and consequent death during surgery. ${ }^{6}$ One large registry-based research showed a higher mortality within a day after surgery in patients who underwent cemented hemiarthroplasty. ${ }^{7}$ A recent meta-analysis also suggested a higher short-term mortality in cemented hemiarthroplasty. ${ }^{5}$ However, the conclusion on whether to use cemented or cementless hemiarthroplasty is still controversial. ${ }^{5,8}$ In addition, although BCIS is a well-known risk factor of acute surgical complication during surgery, little has been known about the attributable risk or complication of the increased short-term mortality other than BCIS in cemented hemiarthroplasty. Therefore, we hypothesized that, in addition to BICS, certain types of complication would contribute the higher mortality in cemented hemiarthroplasty. The aim of this study was to investigate the trajectory of short-term mortality and evaluate the attributable complication that may cause in-hospital death. We used a large nationwide database to investigate rare complications during hospitalization and performed a propensity-score matching analysis to balance the heterogeneous patient backgrounds to obtain robust results.

\section{Methods}

\section{Data Source}

We used the Japanese Diagnosis Procedure Combination inpatient database, which is a nationwide database including discharge abstracts and administrative claims data from 1133 hospitals in Japan. Patient baseline characteristics, primary diagnoses for admission, score for activities of daily living (ADL), comorbidities present upon admission, complications after admission, surgical procedures, and length of hospital stay were recorded in the database. The medical diagnosis, comorbidities, and complications recorded in the database are described with the International Classification of Disease and Related Health Problems, Tenth Revision (ICD-
10), $\operatorname{codes}^{9}$ (Appendix 1,2). The previous validation study reported approximately $80 \%$ sensitivity and $90 \%$ specificity in these diagnostic and procedural records. ${ }^{10}$

\section{Study Population}

Our study participants were all consecutive patients hospitalized with a primary diagnosis of femoral neck fracture (ICD-10 S7200) who underwent hemiarthroplasty (Hemiarthroplasty, K0811; an originally developed operation code in the database), between April 1, 2010, and March 31, 2016. Patients $>60$ years of age were included and those who waited for surgery for $>30$ days were excluded in the investigation for acute elderly patients with femoral neck fractures. We have categorized cemented hemiarthroplasty group as patients who used bone cement in the surgery in addition to hemiarthroplasty procedure.

\section{Main Exposure and Clinical Outcomes}

The surgical interventions were categorized into either hemiarthroplasty with cement use or hemiarthroplasty without cement use. The primary outcome was in-hospital mortality and postoperative 1- to 10-day mortality. The secondary outcomes were in-hospital complications, anesthesia time, intensive care unit (ICU) admission, blood transfusion, and length of hospital stay. Postoperative complications were defined as follows on the basis of previous research: ${ }^{5}$ coronary heart disease, heart failure, respiratory disorders, pulmonary embolism, stroke, renal failure, urinary tract infection, sepsis, surgical site infection, and hip dislocation.

\section{Covariates}

To assess the patients' individual characteristics, data on age, sex, body mass index (BMI), smoking history, comorbidities at admission, anticoagulant use before surgery, the ability to transfer from bed to a chair on admission based on the Barthel Index (BI), waiting time for surgery, the types of anesthesia, and admission through the emergency department were evaluated. To assess hospital characteristics, teaching hospital status, hospital volume, and annual surgical volume for hip fracture surgery were evaluated. The annual surgical volume was defined as the annual number of patients who underwent hemiarthroplasty at each hospital. BMI was classified as $<18.5,18.5-24.9,25.0-29.9$, and $>30.0 \mathrm{~kg} / \mathrm{m}^{2}$. On the basis of the components of the Carlson Comorbidity Index (CCI), congestive heart failure; peripheral vascular disease; myocardial infarction; heart failure; peripheral vascular disease; stroke; dementia; pulmonary disorders; peptic ulcer; mild, moderate, and severe diseases; diabetes with or 
without complications; hemiplegia; renal failure; cancer; metastatic cancer; and human immunodeficiency virus were evaluated. ${ }^{11,12}$ In addition to CCI, Parkinson's disease, stable angina, hypertension, and anemia were assessed. ADL was evaluated using the BI, which is an ordinal scale that measures ADL performance, and the ability to transfer was also evaluated. $^{13}$

\section{Statistical Analyses}

We used a propensity-score matching analysis to identify our cohort of patients with similar baseline characteristics to consider the differences in baseline characteristics between the cemented and cementless hemiarthroplasty groups. A propensity-score is the conditional probability of receiving a specific intervention such as cemented or cementless hemiarthroplasty on a set of measured baseline covariates. ${ }^{14,15}$ The propensity-score was estimated using a multivariable logistic regression analysis, calculating the probability of receiving cemented hemiarthroplasty with adjustment for all the baseline characteristics described in Table 1 (Appendix 3 in detail). Then, the patients were matched between the cemented and cementless hemiarthroplasty groups with a 1:1 matching protocol without replacements. To obtain a balanced matched cohort, we set the caliper width to $20 \%$ of the standard deviation of the logit of the propensity-score. The balance of the baseline characteristic between the two groups was evaluated by comparing standardized differences for all the baseline covariates before and after matching. Standardized differences $<10 \%$ for a given baseline covariates were considered as relatively balanced matching. ${ }^{16}$ In the matched cohort, we used a Cox regression model with a robust variance estimator to estimate the time to death during hospitalization from day 1 to day 14 after surgery. The type I error probability was set to 0.05 for all the analyses. All statistical analyses were performed using Stata version 16.1 (Stata Corp, College Station, TX, USA).

\section{Ethics, Data-Sharing, Funding, and Potential Conflicts of Interest}

The study was approved by the Tokyo Medical and Dental University Ethical Committee and written informed consent was waived by the Ethics Committee (IRB: M2000788). This study was conducted in accordance with the Declaration of Helsinki. Data cannot be shared due to the protection of private information. All authors declare no conflicts of interest for this research. All authors have read and agreed to the published version of the manuscript. This research did not receive grants from any funding agency in the public, commercial or not-for-profit sectors.

\section{Results \\ Study Population}

A total of 113,678 patients (mean [SD] age, 82.07 [7.38] years) were included in the study, of whom 113,678 (88\%) underwent cementless hemiarthroplasty and 15,690 (12\%) underwent cemented hemiarthroplasty (Figure 1, Table 1). More aged women (cemented, 83 years vs cementless, 82 years; $80.9 \%$ vs $78.3 \%)$ with lower BMI (<18.5; $28.8 \%$ vs $26.2 \%)$, less smoking (9.5\% vs $10.6 \%)$, and better ability to transfer (light assist; $9.4 \%$ vs $7.8 \%$ ) underwent cemented hemiarthroplasty. The waiting time for surgery was longer in the cemented hemiarthroplasty group $\quad>72$ hours; $60.3 \%$ vs $56.7 \%$ ). Hospitals with higher number of beds $(>500 ; 7.0 \%$ vs $4.3 \%)$ and lower annual surgical volumes $(<100,98.5 \%$ vs $97 \%)$ were likely to perform cemented hemiarthroplasty. We found no significant difference in comorbidity between the two groups.

\section{Outcomes After Matching}

A total of 31,332 patients, including 15,666 pairs of patients who underwent cemented and cementless hemiarthroplasties, were obtained after the propensity-score matching. The standardized difference between the two groups was $<10 \%$ for all the baseline characteristics including waiting time for surgery; thus, balanced matching was achieved (Table 1).

Table 2 shows the primary and secondary outcomes after matching. After matching, the in-hospital mortality was $0.6 \%(\mathrm{n}=181)$, and no significant association was observed between in-hospital mortality and cemented hemiarthroplasty (hazard ratio [95\% confidence interval, $\mathrm{CI}], 1.2$ [0.89-1.6], $\mathrm{p}=0.23$ ). Figure 2 shows the association between cemented hemiarthroplasty and mortality during early days after surgery. Within the 1 and 10 postoperative days, mortality was significantly higher in the cemented group than in the cementless group, especially in the earlier stage of hospitalization, but the difference in the incidence of death between the two groups narrowed as time passed and after 11 postoperative days, the significant difference diminished (day 1; HR [95\% CI]: 3.5 [1.6-7.68]; day 10; HR [95\% CI]: 1.59 [1.07-2.37]). 


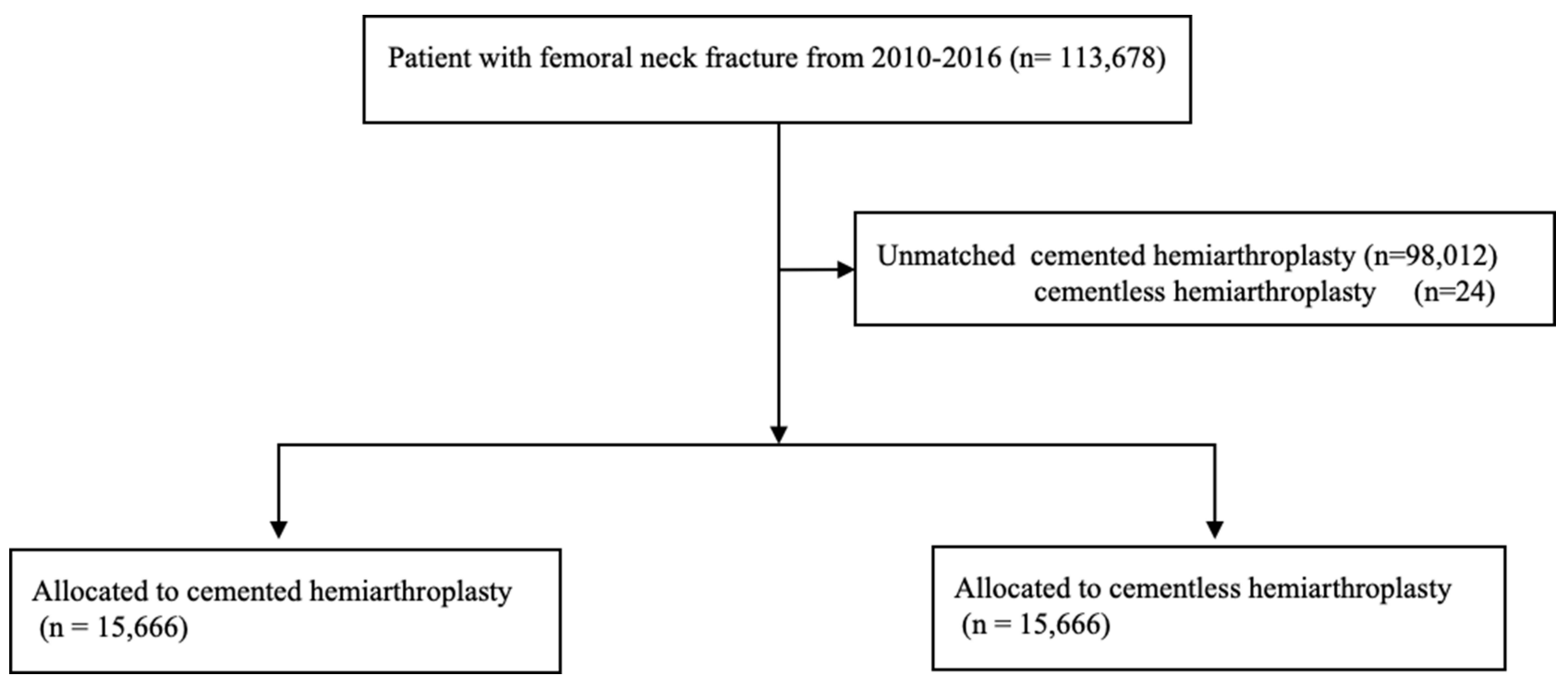

Figure I Flow chart of patient selection.

Among all complications, the patients who underwent cemented hemiarthroplasty had a significantly higher incidence of stroke (odds ratio, OR [95\% CI], 1.55 [1.22-1.97], $\mathrm{p}<0.001$ ), ICU admission (OR [95\% CI], 1.42 [1.25-1.61], $\mathrm{p}<0.001)$, hip dislocation (1.79 [1.12-2.84], $\mathrm{p}=0.014)$, and blood transfusion (OR [95\% CI], 1.24 [1.18-1.31], p < 0.001). In cemented hemiarthroplasty, anesthesia time was significantly longer (mean difference $[95 \% \mathrm{CI}], 18.6 \mathrm{~min}$ [17.3-19.9], $\mathrm{p}<0.001)$. On the other hand, the length of hospital stay was significantly shorter in cemented hemiarthroplasty (mean difference $[95 \% \mathrm{CI}],-0.8$ days $[-1.3--0.3]$, $\mathrm{p}=0.003)$. We found no significant difference in other complications between the cemented and cementless hemiarthroplasty groups.

\section{Discussion}

We performed a propensity-score matching analysis using data from a nationwide multicenter database, including 31,332 patients who underwent hemiarthroplasty. Our study shows no significant difference in 30-day in-hospital mortality between the cemented and cementless hemiarthroplasty groups, although 1- to 10-day postoperative mortality rates were significantly higher in the cemented hemiarthroplasty group than in the cementless hemiarthroplasty group. In addition, this association was highest immediately after surgery, and it reduced as the postoperative period increased. We found that the risk of stroke was significantly higher in cemented hemiarthroplasty group compared to cementless group, which was a potential complication that may increase short-term mortality in cemented hemiarthroplasty.

\section{Mortality}

No significant difference in mortality was found between the cemented and cementless hemiarthroplasty groups. Previous research showed controversial results regarding cemented hip arthroplasty and mortality. Recent RCTs showed no significant difference between cemented and cementless hemiarthroplasties in in-hospital and 30-day mortality rates, which is similar to the result we obtained during our observation period. ${ }^{17,18}$ However, a recent meta-analysis showed a significantly higher mortality at 2 days after operation in the cemented group than in the cementless group. ${ }^{5}$ Our result also showed a significantly higher incidence of death, especially in the early day of postoperative observational period and this association lasted for 10 days after surgery, although this association reduced with the passage of days after surgery.

\section{Complications}

The incidence of stroke and ICU admission were significantly higher in the cemented hemiarthroplasty group than in the cementless hemiarthroplasty group. Among the systemic complications, only stroke showed a significant increase in the cemented hemiarthroplasty group as compared with the cementless hemiarthroplasty group. One plausible explanation is that hypotension during surgery was caused by the cemented implantation. Cementing into bone marrow may cause steep blood pressure reduction, and this phenomenon is known as BCIS. ${ }^{6}$ Thus, decreased blood pressure could cause perioperative stroke in patients who underwent cemented hemiarthroplasty. Previous 
Table I Patient Characteristics

\begin{tabular}{|c|c|c|c|c|c|c|}
\hline & Cemented & Cementless & SMD & Cemented & Cementless & SMD \\
\hline & $N=15,690$ & $N=1 \mid 3,678$ & & $N=15,666$ & $N=15,666$ & \\
\hline Age, year mean (SD) & $83.09(7.31)$ & $82.07(7.38)$ & $13.9 \%$ & $83.09(7.31)$ & $83.17(7.24)$ & $1.2 \%$ \\
\hline Sex, n (\%) & 12,695 (80.9) & $89,056(78.3)$ & $6.4 \%$ & I2,675 (80.9) & 12,776 (81.6) & $1.7 \%$ \\
\hline BMI, n (\%) & & & $6.9 \%$ & & & $2.1 \%$ \\
\hline$<18.5$ & $4514(28.8)$ & $29,818(26.2)$ & & $4503(28.7)$ & $4591(29.3)$ & \\
\hline $18.5-25$ & 8432 (53.7) & 64,17। (56.4) & & $8420(53.7)$ & $8433(53.8)$ & \\
\hline $25-30$ & $1237(7.9)$ & $9604(8.4)$ & & $1237(7.9)$ & $1213(7.7)$ & \\
\hline$\geq 30$ & $162(1.0)$ & $1167(1.0)$ & & $162(1.0)$ & $146(0.9)$ & \\
\hline Missing & $1345(8.6)$ & $8918(7.8)$ & & $1344(8.6)$ & $1283(8.2)$ & \\
\hline Smoking, n (\%) & & & $3.8 \%$ & & & $1.6 \%$ \\
\hline Never-smoking & $12,890(82.2)$ & $92,07 \mid(81.0)$ & & 12,866 (82.1) & $|2,96|(82.7)$ & \\
\hline Smoking & $1483(9.5)$ & $12,044(10.6)$ & & I $483(9.5)$ & $1419(9.1)$ & \\
\hline Missing & $1317(8.4)$ & $9563(8.4)$ & & $1317(8.4)$ & $1286(8.2)$ & \\
\hline Charlson Comobidity Index, n (\%) & & & $1.1 \%$ & & & $3.6 \%$ \\
\hline 0 & $7555(48.2)$ & $54,668(48.1)$ & & 7544 (48.2) & $7822(49.9)$ & \\
\hline 1 & $4794(30.6)$ & $35,084(30.9)$ & & $4788(30.6)$ & $4635(29.6)$ & \\
\hline 2 & $2254(14.4)$ & 16,333 (14.4) & & $2249(14.4)$ & $2162(13.8)$ & \\
\hline$\geq 3$ & $1087(6.9)$ & $7593(6.7)$ & & $1085(6.9)$ & $1047(6.7)$ & \\
\hline Anemia, n (\%) & $531(3.4)$ & $3456(3.0)$ & $2.0 \%$ & $529(3.4)$ & $480(3.1)$ & $1.8 \%$ \\
\hline Hip Osteoarthritis, n (\%) & $24(0.2)$ & $145(0.1)$ & $0.7 \%$ & $24(0.2)$ & $24(0.2)$ & $0.1 \%$ \\
\hline Anticoagulant before surgery, $\mathrm{n}(\%)$ & $5885(37.5)$ & $40,038(35.2)$ & $4.8 \%$ & $5865(37.4)$ & $5778(36.9)$ & $1.1 \%$ \\
\hline Ability to transfer, $\mathrm{n}(\%)$ & & & $6.1 \%$ & & & $3.4 \%$ \\
\hline Unable & II,023 (70.3) & $82,296(72.4)$ & & II,010 (70.3) & $11,216(7 \mid .6)$ & \\
\hline Heavy assist & $1400(8.9)$ & 10,094 (8.9) & & $1395(8.9)$ & $1300(8.3)$ & \\
\hline Light assist & $1425(9.1)$ & $8828(7.8)$ & & $142 \mid(9.1)$ & $142 \mid(9.1)$ & \\
\hline Independent & II $64(7.4)$ & $8275(7.3)$ & & $1162(7.4)$ & $1079(6.9)$ & \\
\hline Missing & $678(4.3)$ & $4185(3.7)$ & & $678(4.3)$ & $650(4.1)$ & \\
\hline Waiting time (Hr), n (\%) & & & $7.4 \%$ & & & $0.3 \%$ \\
\hline Less than 72 & $6226(39.7)$ & $49,272(43.3)$ & $4.9 \%$ & $6223(39.7)$ & 6244 (39.9) & \\
\hline More than 72 & $9464(60.3)$ & $64,406(56.7)$ & & $9443(60.3)$ & $9422(60.1)$ & \\
\hline Anesthesia, n (\%) & & & $4.9 \%$ & & & $3.2 \%$ \\
\hline General Anesthesia & $8624(55.0)$ & $64,694(56.9)$ & & $8622(55.0)$ & $8726(55.7)$ & \\
\hline Spinal Anesthesia & $6270(40.0)$ & $43,267(38.1)$ & & 6249 (39.9) & 6249 (39.9) & \\
\hline General and Epidural & $770(4.9)$ & $5385(4.7)$ & & $769(4.9)$ & $669(4.3)$ & \\
\hline Spinal and Epidural & $26(0.2)$ & $332(0.3)$ & & $26(0.2)$ & $22(0.1)$ & \\
\hline Admission through ER, n (\%) & 13,327 (84.9) & $101,213(89.0)$ & $12.2 \%$ & 13,323 (85.0) & $|3,35|(85.2)$ & $0.5 \%$ \\
\hline Teaching hospital, n (\%) & $640(4.1)$ & $3048(2.7)$ & $7.7 \%$ & $640(4.1)$ & $620(4.0)$ & $0.6 \%$ \\
\hline Hospital volume, n (\%) & & & $18.4 \%$ & & & $1.6 \%$ \\
\hline Less than 20 & $249(1.6)$ & $387(0.3)$ & & $225(1.4)$ & $221(1.4)$ & \\
\hline 20 to 100 & $3204(20.4)$ & $27,091(23.8)$ & & $3204(20.5)$ & $3154(20.1)$ & \\
\hline 100 to 500 & $11,145(71.0)$ & $81,279(71.5)$ & & $11,145(71.1)$ & II,249 (7I.8) & \\
\hline More than 500 & $1092(7.0)$ & $4921(4.3)$ & & $1092(7.0)$ & $1042(6.7)$ & \\
\hline Annual surgical volume, n (\%) & & & $10.2 \%$ & & & $1.4 \%$ \\
\hline Less than 100 & 15,450 (98.5) & $110,212(97.0)$ & & 15,426 (98.5) & 15,453 (98.6) & \\
\hline More than 100 & $240(1.5)$ & $3466(3.0)$ & & $240(1.5)$ & $213(1.4)$ & \\
\hline Admission on weekend, $\mathrm{n}(\%)$ & $3129(19.9)$ & $23,426(20.6)$ & $1.7 \%$ & $3125(19.9)$ & $3033(19.4)$ & $1.5 \%$ \\
\hline
\end{tabular}

Abbreviation: SMD, standardized mean difference. 
Table 2 Postoperative Complications Between the Propensity Score Matched Groups

\begin{tabular}{|c|c|c|c|c|}
\hline & \multirow{2}{*}{$\begin{array}{l}\text { Cemented } \\
N=15,666\end{array}$} & \multirow{2}{*}{$\begin{array}{l}\text { Cementless } \\
N=15,666\end{array}$} & \multirow[t]{2}{*}{ HR (95\% Cl) } & \multirow[t]{2}{*}{ p-value } \\
\hline & & & & \\
\hline In-hospital mortality, n (\%) & $193(1.2)$ & $180(I . I)$ & I.2 (0.89-I.6) & 0.23 \\
\hline Post surgical first two day mortality, n (\%) & $28(0.2)$ & $8(0.1)$ & $3.5(1.6-7.68)$ & 0.002 \\
\hline \multirow[t]{2}{*}{ Post surgical first seven day mortality, n (\%) } & $50(0.3)$ & $28(0.2)$ & $1.79(1.12-2.84)$ & 0.014 \\
\hline & Cemented & Cementless & OR (95\% C.I.) & $\mathrm{p}$-value \\
\hline Coronary Heart Disease, n (\%) & $294(1.9)$ & $282(1.8)$ & $1.05(0.89-1.24)$ & 0.58 \\
\hline Heart Failure, n (\%) & $230(1.5)$ & $216(1.4)$ & $1.07(0.88-1.29)$ & 0.50 \\
\hline Respiratory Disorders, n (\%) & $429(2.7)$ & $410(2.6)$ & $1.05(0.92-1.2)$ & 0.48 \\
\hline Pulmonary Embolism, n (\%) & $75(0.5)$ & $85(0.5)$ & $0.89(0.65-1.22)$ & 0.47 \\
\hline Stroke, n (\%) & $173(1.1)$ & $112(0.7)$ & $1.55(1.22-1.97)$ & $<0.001$ \\
\hline Renal Failure, n (\%) & $69(0.4)$ & $75(0.5)$ & $0.92(0.66-1.28)$ & 0.62 \\
\hline Urinary Tract Infection, n (\%) & $428(2.7)$ & $377(2.4)$ & $1.14(0.99-1.31)$ & 0.06 \\
\hline Sepsis, n (\%) & $65(0.4)$ & $72(0.5)$ & $0.9(0.64-1.26)$ & 0.55 \\
\hline ICU admission, n (\%) & $619(4.0)$ & $442(2.8)$ & $1.42(I .25-1.6 I)$ & $<0.001$ \\
\hline Blood Transfusion, n (\%) & $3413(21.8)$ & $2869(18.3)$ & $1.24(1 . \mid 8-1.31)$ & $<0.001$ \\
\hline Surgical site infection, $\mathrm{n}$ (\%) & $163(1.0)$ & $133(0.8)$ & $1.23(0.98-1.55)$ & 0.08 \\
\hline \multirow[t]{2}{*}{ Hip dislocation, n (\%) } & $132(0.8)$ & $95(0.6)$ & $1.79(1.12-2.84)$ & 0.014 \\
\hline & Cemented & Cementless & MD (95\% C.I.) & $\mathrm{p}$-value \\
\hline Anesthesia time, min mean (SD) & I26.3 (40.8) & $107.7(70.3)$ & $18.6(17.3-19.9)$ & $<0.001$ \\
\hline Length of hospital stay, day mean (SD) & $35.1(23.7)$ & $35.9(23.8)$ & $-0.8(-1.3--0.3)$ & 0.003 \\
\hline Medical cost, per $\$ 10$ mean $(S D)$ & $2222.5(943.4)$ & $2285.7(908.9)$ & $-63.6(-84.1--43.1)$ & $<0.001$ \\
\hline
\end{tabular}

Note: In-hospital mortality was estimated using a cox regression model, and other outcomes were estimated using logistic regression model.

Abbreviations: $\mathrm{HR}$, hazard ratio; OR, odds ratio; $\mathrm{MD}$, mean difference; $\mathrm{Cl}$, confidence interval.

research in heart surgery reported that $>40 \%$ decrease in blood pressure during surgery caused approximately $20 \%$ higher risk of poor neurological outcome. ${ }^{19}$ Although our database did not include the day on which the complication occurred, this sudden plunge of blood pressure during surgery may cause the risk of stroke, suggesting higher mortality especially in the early days of hospitalization. The symptoms of stroke are less obvious, especially in elderly population, and the outcomes worsen with an increase in the patients' age. ${ }^{20}$ When compared with patients whose age ranged in their $60 \mathrm{~s}$, the prevalence of asymptomatic stroke was twice in patients whose age ranged in their $80 \mathrm{~s}^{21}$ Thus, it is important to closely monitor subtle changes in patient cognition. Along with a higher incidence of stroke, the ICU admission rate was also significantly higher in the cemented hemiarthroplasty group than in the cementless hemiarthroplasty group.

Our result showed a significantly higher risk of hip dislocation in the cemented hemiarthroplasty group. This result is consistent with a previous report. Jameson et al reported 1.85 times higher risk of dislocation in cemented hemiarthroplasty than in cementless hemiarthroplasty. ${ }^{22}$ On the other hand, the authors reported the risk of revision surgery was approximately three times higher in cementless hemiarthroplasty over an 18-month observation period; thus, the higher dislocation risk in the cemented group was not reflected in the higher incidence of revision surgery from a long-term perspective.

Anesthesia time and the incidence of blood transfusion were significantly greater in the cemented hemiarthroplasty group than in the cementless hemiarthroplasty group. The time for anesthesia was 18 minutes longer on average, and the risk of blood transfusion was $24 \%$ higher in cemented hemiarthroplasty in our research. These results were consistent with those of previous RCTs. Three RCTs showed 12 to 18 minutes longer operation time in patients who underwent cemented hemiarthroplasty. ${ }^{7,18,23}$ This longer operation times could also cause higher blood transfusion rates. Two of three RCTs also reported higher amounts of blood loss in the cemented group $(75-90 \mathrm{~mL}))^{7,18}$

Although incidence of stroke, ICU admission, and hip dislocation was significantly higher in cemented 


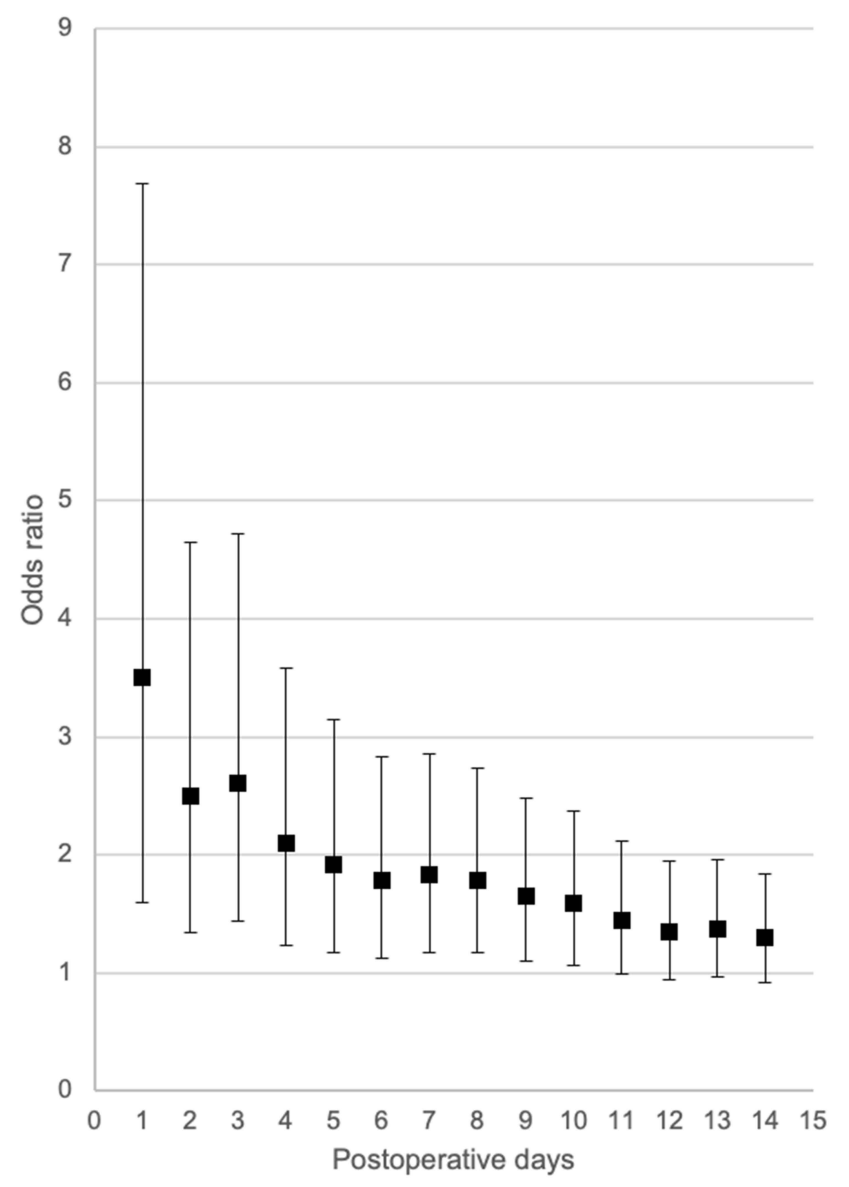

Figure 2 Association between cemented hemiarthroplasty and short-term mortality.

hemiarthroplasty group, the length of hospital stay was 0.8 days shorter in cemented group $(p=0.003)$. The possible explanations of this paradoxical result were higher mortality and possible faster recovery in mobile function to be discharged from hospital in patient who underwent cemented hemiarthroplasty compared to cementless hemiarthroplasty. Since the short-time mortality was higher in the cemented group compared to cementless group, this earlier death could reduce the length of hospital stay. In addition, even the incidence of stroke, ICU admission, and hip dislocation was higher in cemented group compared to cementless group, the absolute number of complication was small, and thus overall effect of cemented hemiarthroplasty on faster recovery in mobile function led to earlier discharge from hospital. Patients who underwent cemented hemiarthroplasty were reported to experienced reduced pain and this may contribute to faster recovery in physical function of cemented hemiarthroplasty group although long-term functional recovery is inconclusive. ${ }^{24,25}$ In this study, the risk differences of stroke, ICU admission, and hip dislocation between cemented and cementless hemiarthroplasty groups were as relatively low as $0.4 \%$, $1.2 \%, 0.2 \%$, respectively. Therefore, even the risk of these complications was higher in cemented hemiarthroplasty group compared to cementless group, the benefit of early functional recovery canceled out these negative effects, resulting in overall shorter length of hospital stays in cemented hemiarthroplasty group.

\section{Strength and Limitations}

To investigate short-term mortality and complications, we used propensity-score matching analysis using 31,322 cases after matching from 113,678 patients that enabled us to obtain robust estimation. In addition, we evaluated the short-term mortality without selecting arbitrary day to define the short-term mortality to capture the trend of mortality within the observation period. The present study also has some limitations. First, time to complication was not recorded in the database. Therefore, the higher incidence of stroke in cemented hemiarthroplasty group does not surely explain the cause of death. However, stroke still is one of the major morbidities after hip fracture and our result is relevant. ${ }^{26}$ Second, surgical approaches were not recorded in our database. Some research reported higher dislocation risk with posterior approach hemiarthroplasty and the difference in these surgical approaches could be potential confounders. ${ }^{27}$ Third, our database does not include information about each surgeon's skills, experience, and the preference in hip fracture management such as VTE prophylaxis protocol. Considering the risk of complications after surgery, surgeries performed by skilled surgeons would confer a lower risk of complications. Instead, we included information about annual surgical volume to take into account the surgeon's skills. Fourth, our database does not include the severity of complications. To consider this problem, we also included ICU admission as a secondary outcome to estimate the severity of complications. Fifth, the criteria of hospital discharge differ over each institution and attending surgeon. Therefore, the interpretation of shorter length of hospital stay in cemented hemiarthroplasty group should be careful. To mitigate the bias of different institution, we adjusted institutional characteristics including teaching status, hospital volume, and annual surgical volume. 


\section{Conclusions}

Although there was no significant difference in 30-day inhospital mortality between cemented and cementless hemiarthroplasty, the mortality rates from day 1 to day 10 after surgery were significantly higher in cemented hemiarthroplasty as well as the incidence of stroke. The risk of stroke should be considered especially in cemented hemiarthroplasty during the early days after the surgery to optimize health care resources and improve clinical outcomes.

\section{Disclosure}

Dr Tetsuya Jinno reports personal fees from Stryker, personal fees from Depuy Synthes, personal fees from Zimmer Biomet, outside the submitted work. The authors report no other conflicts of interest in this work.

\section{References}

1. Burge R, Dawson-Hughes B, Solomon DH, Wong JB, King A, Tosteson A. Incidence and economic burden of osteoporosis-related fractures in the United States, 2005-2025. J Bone Miner Res. 2007;22(3):465-475. doi:10.1359/jbmr.061113

2. Cooper C, Campion G, Melton LJ 3rd. Hip fractures in the elderly: a world-wide projection. Osteoporos Int. 1992;2(6):285-289. doi:10.1007/BF01623184

3. Miyamoto RG, Kaplan KM, Levine BR, Egol KA, Zuckerman JD. Surgical management of hip fractures: an evidence-based review of the literature. I: femoral neck fractures. $\mathrm{J} \mathrm{Am} \mathrm{Acad} \mathrm{Orthop}$ Surg. 2008;16(10):596-607. doi:10.5435/00124635-20081000000005

4. Veldman HD, Heyligers IC, Grimm B, Boymans TAEJ. Cemented versus cementless hemiarthroplasty for a displaced fracture of the femoral neck. Bone Joint J. 2017;99-B(4):421-431. doi:10.1302/ 0301-620X.99B4.BJJ-2016-0758.R1

5. Fenelon C, Murphy EP, Pomeroy E, Murphy RP, Curtin W, Murphy CG. Perioperative mortality after cemented or uncemented hemiarthroplasty for displaced femoral neck fractures - a systematic review and meta-analysis. $J$ Arthroplasty. 2020.

6. Donaldson AJ, Thomson HE, Harper NJ, Kenny NW. Bone cement implantation syndrome. $B r \quad J$ Anaesth. 2009;102(1):12-22. doi:10.1093/bja/aen328

7. Talsnes O, Vinje T, Gjertsen JE, et al. Perioperative mortality in hip fracture patients treated with cemented and uncemented hemiprosthesis: a register study of 11,210 patients. Int Orthop. 2013;37 (6):1135-1140. doi:10.1007/s00264-013-1851-3

8. Richardson CG, Lethbridge LN, Dunbar MJ. Increased mortality with the use of cementless fixation for femoral neck fractures: analysis of 5883 hip arthroplasty cases. J Arthroplasty. 2020;35(12):3627-3630. doi:10.1016/j.arth.2020.07.006

9. Brämer GR. International statistical classification of diseases and related health problems. Tenth revision. World Health Stat $Q$. 1988;41(1):32-36.

10. Yamana H, Moriwaki M, Horiguchi H, Kodan M, Fushimi K, Yasunaga H. Validity of diagnoses, procedures, and laboratory data in Japanese administrative data. $J$ Epidemiol. 2017;27(10):476-482. doi:10.1016/j.je.2016.09.009
11. Quan H, Sundararajan V, Halfon P, et al. Coding algorithms for defining comorbidities in ICD-9-CM and ICD-10 administrative data. Med Care. 2005;43(11):1130-1139. doi:10.1097/01. mlr.0000182534.19832.83

12. Charlson ME, Pompei P, Ales KL, MacKenzie CR. A new method of classifying prognostic comorbidity in longitudinal studies: development and validation. $J$ Chronic Dis. 1987;40(5):373-383. doi:10.1016/0021-9681(87)90171-8

13. Mahoney FI, Barthel DW. Functional evaluation: the Barthel Index: a simple index of independence useful in scoring improvement in the rehabilitation of the chronically ill. Md State Med J. 1965;14:61-65.

14. Rosenbaum PR, Rubin DB. The central role of the propensity score in observational studies for causal effects. Biometrika. 1983;70 (1):41-55. doi:10.1093/biomet/70.1.41

15. Rubin DB. Using propensity scores to help design observational studies: application to the tobacco litigation. Health Serv Outcomes Res Methodol. 2001;2(3-4):169-188. doi:10.1023/A:1020363010465

16. Austin PC. Balance diagnostics for comparing the distribution of baseline covariates between treatment groups in propensity-score matched samples. Stat Med. 2009;28(25):3083-3107. doi:10.1002/ sim.3697

17. Deangelis JP, Ademi A, Staff I, Lewis CG. Cemented versus uncemented hemiarthroplasty for displaced femoral neck fractures: a prospective randomized trial with early follow-up. $J$ Orthop Trauma. 2012;26(3):135-140. doi:10.1097/BOT.0b013e318238b7a5

18. Langslet E, Frihagen F, Opland V, Madsen JE, Nordsletten L, Figved W. Cemented versus uncemented hemiarthroplasty for displaced femoral neck fractures: 5-year followup of a randomized trial. Clin Orthop Relat Res. 2014;472(4):1291-1299. doi:10.1007/s11999013-3308-9

19. Löwhagen Hendén P, Rentzos A, Karlsson JE, et al. Hypotension during endovascular treatment of ischemic stroke is a risk factor for poor neurological outcome. Stroke. 2015;46(9):2678-2680. doi:10.1161/STROKEAHA.115.009808

20. Chen RL, Balami JS, Esiri MM, Chen LK, Buchan AM. Ischemic stroke in the elderly: an overview of evidence. Nat Rev Neurol. 2010;6(5):256-265. doi:10.1038/nrneurol.2010.36

21. Vermeer SE, Longstreth WT Jr., Koudstaal PJ. Silent brain infarcts: a systematic review. Lancet Neurol. 2007;6(7):611-619. doi:10.1016/ S1474-4422(07)70170-9

22. Jameson SS, Jensen CD, Elson DW, et al. Cemented versus cementless hemiarthroplasty for intracapsular neck of femur fracture a comparison of 60,848 matched patients using national data. Injury. 2013;44(6):730-734. doi:10.1016/j.injury.2012.10.031

23. Santini S, Rebeccato A, Bolgan I, Turi G. Hip fractures in elderly patients treated with bipolar hemiarthroplasty: comparison between cemented and cementless implants. J Orthop Traumatol. 2005;6 (2):80-87. doi:10.1007/s10195-005-0086-5

24. Azegami S, Gurusamy KS, Parker MJ. Cemented versus uncemented hemiarthroplasty for hip fractures: a systematic review of randomised controlled trials. Hip Int. 2011;21(5):509-517. doi:10.5301/ HIP.2011.8640

25. Li N, Zhong L, Wang C, Xu M, Li W. Cemented versus uncemented hemi-arthroplasty for femoral neck fractures in elderly patients: a systematic review and meta-analysis of randomized controlled trials. Medicine (Baltimore). 2020;99(8):e19039. doi:10.1097/ MD.0000000000019039

26. van der Burg DA, Diepstraten M, Wouterse B. Long-term care use after a stroke or femoral fracture and the role of family caregivers. BMC Geriatr. 2020;20(1):150. doi:10.1186/s12877-020-01526-7

27. Rogmark C, Fenstad AM, Leonardsson O, et al. Posterior approach and uncemented stems increases the risk of reoperation after hemiarthroplasties in elderly hip fracture patients. Acta Orthop. 2014;85 (1):18-25. doi:10.3109/17453674.2014.885356 


\section{Publish your work in this journal}

Clinical Interventions in Aging is an international, peer-reviewed journal focusing on evidence-based reports on the value or lack thereof of treatments intended to prevent or delay the onset of maladaptive correlates of aging in human beings. This journal is indexed on PubMed Central, MedLine, CAS, Scopus and the Elsevier
Bibliographic databases. The manuscript management system is completely online and includes a very quick and fair peer-review system, which is all easy to use. Visit http://www.dovepress.com/ testimonials.php to read real quotes from published authors.

Submit your manuscript here: https://www.dovepress.com/clinical-interventions-in-aging-journal 